\title{
Spatial moments of catchment rainfall: rainfall spatial organisation, basin morphology, and flood response
}

\author{
D. Zoccatelli ${ }^{1}$, M. Borga ${ }^{1}$, A. Viglione ${ }^{2}$, G. B. Chirico ${ }^{3}$, and G. Blöschl ${ }^{2}$ \\ ${ }^{1}$ Department of Land and Agroforest Environment, University of Padova, Italy \\ ${ }^{2}$ Institut für Wasserbau und Ingenieurhydrologie, Technische Universität Wien, Vienna, Austria \\ ${ }^{3}$ Dipartimento di Ingegneria Agraria, Università di Napoli Federico II, Naples, Italy
}

Received: 7 June 2011 - Published in Hydrol. Earth Syst. Sci. Discuss.: 21 June 2011

Revised: 15 October 2011 - Accepted: 17 November 2011 - Published: 20 December 2011

\begin{abstract}
This paper describes a set of spatial rainfall statistics (termed "spatial moments of catchment rainfall") quantifying the dependence existing between spatial rainfall organisation, basin morphology and runoff response. These statistics describe the spatial rainfall organisation in terms of concentration and dispersion statistics as a function of the distance measured along the flow routing coordinate. The introduction of these statistics permits derivation of a simple relationship for the quantification of catchment-scale storm velocity. The concept of the catchment-scale storm velocity takes into account the role of relative catchment orientation and morphology with respect to storm motion and kinematics. The paper illustrates the derivation of the statistics from an analytical framework recently proposed in literature and explains the conceptual meaning of the statistics by applying them to five extreme flash floods occurred in various European regions in the period 2002-2007. High resolution radar rainfall fields and a distributed hydrologic model are employed to examine how effective are these statistics in describing the degree of spatial rainfall organisation which is important for runoff modelling. This is obtained by quantifying the effects of neglecting the spatial rainfall variability on flood modelling, with a focus on runoff timing. The size of the study catchments ranges between 36 to $982 \mathrm{~km}^{2}$. The analysis reported here shows that the spatial moments of catchment rainfall can be effectively employed to isolate and describe the features of rainfall spatial organization which have significant impact on runoff simulation. These statistics provide useful information on what space-time scales rainfall has to be monitored, given certain catchment and flood characteristics, and what are the effects of space-time aggregation on flood response modeling.
\end{abstract}

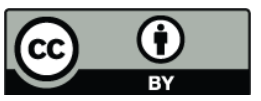

Correspondence to: D. Zoccatelli (davide.zoccatelli@studenti.unipd.it)

\section{Introduction}

Rainfall is a highly heterogeneous process over a wide range of scales both in space and time (e.g. Rodriguez-Iturbe et al., 1998; Fabry, 1996; Marani, 2005). Whether or not spatial heterogeneity of rainfall has an impact on catchment discharge and for what reason, is a problem that has been often addressed in hydrology and that is still poorly understood. Many hydrological studies have focused on the role of rainfall space-time variability in catchment response, with the aim of developing a rationale for more effective catchment monitoring, modelling and forecasting (e.g. Naden, 1992; Obled et al., 1994; Blöschl and Sivapalan, 1995; Bell and Moore, 2000; Andréassian et al., 2001; Morin et al., 2006; Moulin et al., 2008; Saulnier and Le Lay, 2009; Gourley et al., 2011). From a practical perspective, it is important to know at what space-time scales rainfall has to be monitored, given certain catchment and flood characteristics, and what are the effects of space-time aggregations on model simulations (Berne et al., 2004).

An important feature frequently observed in these studies is that catchments act as space-time filters (Skøien and Blöschl, 2006) with specific dampening characteristics to the rainfall input. The filtering properties may be strong enough to efficiently smooth out some features of rainfall spatial variability. This means that only some specific characteristics of rainfall spatial organisation will eventually emerge as runoff spatial and temporal variability (Skøien et al., 2003). Thus we believe there is a need to introduce measures to quantify the catchment filtering effect which, as a function of rainfall organization, basin scale and the heterogeneities embedded in the basin geomorphic structure, control the possible extent of the influence of rainfall spatial organisation on the hydrologic response. We distinguish here between rainfall spatial variability and organization. More specifically, by spatial organization we mean systematic spatial variation of rainfall with respect to certain basin geomorphic properties

Published by Copernicus Publications on behalf of the European Geosciences Union. 
which directly control the runoff response. In this paper, the rainfall spatial organization is analysed with respect to the flow distance, i.e. the distance along the runoff flow path from a given point to the outlet.

Observational and modelling studies have shown that the river network geometry plays a central role in the structure of the catchment dampening properties, particularly for cases of extreme floods when the impact of land properties heterogeneity on runoff generation is less significant with respect to moderate floods and the stream network extends to previously unchanneled topographic elements, hence increasing drainage density and flow response rate of hillslopes (Naden, 1992; Woods and Sivapalan, 1999; Smith et al., 2002; Nicotina et al., 2008; Sangati et al., 2009). Runoff routing through branched channel networks imposes an effective averaging of spatial rainfall excess across locations with equal routing time, in spite of the inherent spatial variability. The flow distance coordinate may be used as a surrogate for travel time, when the hydrograph response is determined mainly by the distribution of travel times, neglecting hydrodynamic dispersion, and variations in runoff propagation celerities may be disregarded. This implies that rainfall spatial organisation measured along the river network by using the flow distance coordinate may be a significant property of rainfall spatial variability when considering flood response modelling.

Various measures of rainfall organisation based on the flow distance coordinate have been introduced in the last decade. Smith et al. (2002, 2005), Zhang et al. (2001) and Borga et al. (2007), in a series of monographs on extreme floods and flash floods, systematically employed a scaled measure of distance from the storm centroid and scaled measures of rainfall variability to quantify the storm spatial organisation and variability from the perspective of a distance metric imposed by the river network. Smith et al. (2004a) examined basin outflow response to observed spatial variability of rainfall for several basins in the Distributed Model Intercomparison Project (Smith et al., 2004b), by using, among other indexes, a rainfall location index based on the distance from the centroid of the catchment to the centroid of the rainfall pattern. They found that all basins except one had a very limited range of rainfall location index, with the rainfall centroid close to the catchment centroid. Interestingly, the catchment displaying the largest range of rainfall location index was also the one characterised by such complexities to suggest the use of a distributed model approach. A similar approach was taken by Syed et al. (2003) who evaluated the ability of simple geometric measures of thunderstorm rainfall in explaining the runoff response from a $148 \mathrm{~km}^{2}$ watershed. They also used a location index similar to that introduced by Smith et al. (2004a). They observed that the position of the storm core relative to the watershed outlet becomes more important as the catchment size increases, with storms positioned in the central portion of the watershed producing more runoff than those positioned near the outlet or near the head of the watershed. Woods and Sivapalan (1999) proposed an analytical method to identify the importance of different components of the hydrological cycle during storm events in humid temperate catchments. They expressed the mean catchment runoff time as a function of the distance from the centroid of the catchment to the centroid of the rainfall excess pattern measured along the flow distance coordinate. This term summarised the influence of the rainfall spatial variability on the timing of the flood peak discharge in their model. However, the extent of potential application of this method is limited by the assumption of multiplicative space-time separability for both rainfall and runoff generation processes. This implies that the storm event is assumed to be stationary, i.e. it does not move over the catchment. This assumption is relaxed in the analytical framework introduced by Viglione et al. (2010a), which describes the dependence of the catchment flood response on the space-time interactions between rainfall, runoff generation and routing mechanisms. Notably, this method affords examination of the effects of storm movement on runoff properties.

This paper builds upon the work presented in Woods and Sivapalan (1999) and Viglione et al. (2010a, b). The framework developed in these papers quantifies the contributions of the space-time variability of precipitation, runoff coefficient, hillslope and channel routing to the flood runoff volume and the delay and spread of the resulting hydrograph. The aim there was to analyse rainfall-runoff events (and ways of modeling them) by subdividing the characteristics of the hydrological response into its components. In the present work we reorganise some of these components, by introducing a set of statistics of spatial rainfall organisation measured along the flow distance which are relevant to the analysis of the runoff response. These statistics, termed "spatial moments of catchment rainfall", are dimensionless numbers that can be used to establish relationships valid over a wide range of scales. They provide a synthesis of the interaction between rainfall and basin morphometric properties and are useful similarity measures for "comparative hydrology" studies (see e.g. McDonnell and Woods, 2004; Blöschl, 2006). For instance, in this work we show, both analytically and empirically, how these statistics can be used to quantify the influence of spatial rainfall organization on flood hydrograph characteristics and we compare a number of events in several catchments. The method based on the spatial moments of catchment rainfall provides a theoretical foundation for various measures of rainfall spatial variability based on the flow distance coordinate, which have been reported in the literature in the last decade (Smith et al., 2002, 2005; Syed et al., 2003; Sangati et al., 2009). Moreover, they extend to the case of runoff propagation under condition of spatial rainfall variability the concept of spatial moments used for analysis of solute transport in porous media (Goltz and Roberts, 1987). The development of this similarity, which is not pursued in this paper but is subject of current investigation, aims to order theoretical results that appeared in disparate fields into a 
coherent theoretical framework for both hydrologic flow and transport, as shown by Rinaldo et al. (2006).

As part of this analysis, we show how the introduction of the spatial moments of catchment rainfall permits derivation of a simple relationship for the quantification of storm velocity at the catchment scale. The importance of storm movement on surface runoff has been investigated for nearly four decades (Maksimov, 1964; Surkan, 1974; Ogden et al., 1995; Singh, 1998; de Lima and Singh, 2002). However, to the best of our knowledge, these works are based on "virtual experiments" using idealized storm profiles and motion as input to watershed models. Results seem to support the conclusion that catchment response is sensitive to storm motion relative to catchment morphology, depending on different processes and scales. With this work we show how it is possible to isolate and quantify the "catchment scale storm velocity", generated by imposing a prescribed space-time storm variability to the catchment morphological properties.

In the following developments, we disregard the differentiation between hillslopes and channel network to the total runoff travel time. While the methodology can be easily extended to include a hillslope term, we prefer here to focus on the interaction between the morphological catchment properties and rainfall organisation. On going investigations are aimed to examine the impact of varying the hillslope residence time on both the spatial moments of catchment rainfall and the catchment scale storm velocity.

The conceptual meaning of the spatial moments is illustrated by analysing five extreme flash floods occurred in various European regions in the period 2002-2007. High resolution, carefully controlled, radar rainfall fields and a spatially distributed hydrologic model are employed to examine the use of these statistics to describe the degree of spatial rainfall organisation which is important for runoff modelling, with a focus on runoff timing. The size of the study catchments ranges between 36 to $982 \mathrm{~km}^{2}$. Hillslope residence time and spatial variability of runoff ratio, which are disregarded in the derivation of the spatial moments, are included in the distributed hydrological model. Therefore, contrasting model results with information inferred from the spatial moments provides a necessary evaluation of the impact of the working assumptions on the use of these statistics, at least in the context of extreme floods.

The outline of the paper is as follows. In Sect. 2 we define the statistics termed "spatial moments of catchment rainfall". In Sect. 3 we show how these rainfall statistics can be related to the flood hydrograph properties. Section 4 is devoted to illustrate the derivation of the spatial moments of catchment rainfall for the five flood events. In Sect. 5 we perform numerical experiments in which modelled flood response obtained by using detailed spatial input is contrasted with the corresponding flash flood response obtained by using spatially uniform rainfall. Runoff model sensitivity to spatial organisation of rainfall is examined by exploiting the spatial rainfall statistics. Section 6 completes the paper with discussion and conclusions.

\section{Spatial moments of catchment rainfall: definitions}

Spatial moments of catchment rainfall provide a description of overall spatial rainfall organisation at a certain time $t$, as a function of the rainfall field $r(x, y, t)\left(\mathrm{L} \mathrm{T}^{-1}\right)$ value at any position $x, y$ inside the watershed and of the distance $d(x, y)(\mathrm{L})$ between the position $x, y$ and the catchment outlet measured along the flow path. The spatial moments of catchment rainfalls are defined after rearranging some of the covariance terms employed in Viglione et al. (2010a) to represent the mean and the variance of the network travel time, under the hypothesis of constant flow velocity (Appendix). The $n$-th spatial moment of catchment rainfall $p_{n}\left(\mathrm{~L}^{n+1} \mathrm{~T}^{-1}\right)$ is expressed as:

$p_{n}(t)=|A|^{-1} \int_{A} r(x, y, t) d(x, y)^{n} d A$

where $A\left(\mathrm{~L}^{2}\right)$ is the spatial domain of the drainage basin. The zero-th order spatial moment $p_{0}(t)$ yields the average catchment rainfall rate at time $t$.

Analogously, the $g_{n}\left(\mathrm{~L}^{n}\right)$ moments of the flow distance are given by:

$g_{n}=|A|^{-1} \int_{A} d(x, y)^{n} d A$.

The zero-th order spatial moment of flow distance yields unity. Non-dimensional (scaled) spatial moments of catchment rainfall can be obtained by taking the ratio between the spatial moments of catchment rainfall and the moments of the flow distance, as follows, for the first two orders:

$$
\begin{aligned}
\delta_{1}(t) & =\frac{p_{1}(t)}{p_{0}(t) g_{1}} \\
\delta_{2}(t) & =\frac{A^{-1} \int_{A} r(x, y, t)\left[d(x, y)-\delta_{1}(t) g_{1}\right]^{2} d A}{A^{-1} \int_{A} r(x, y, t) d A \quad A^{-1} \int_{A}\left[d(x, y)-g_{1}\right]^{2} d A} \\
& =\frac{1}{g_{2}-g_{1}^{2}}\left[\frac{p_{2}(t)}{p_{0}(t)}-\left(\frac{p_{1}(t)}{p_{0}(t)}\right)^{2}\right]
\end{aligned}
$$

where for the second order the central moment is reported. The first scaled moment $\delta_{1}(-)$ describes the distance of the centroid of catchment rainfall with respect to the average value of the flow distance (i.e. the catchment centroid). Values of $\delta_{1}$ close to 1 reflect a rainfall distribution either concentrated close to the position of the catchment centroid or spatially homogeneous, with values less than one indicating that rainfall is distributed near the basin outlet, and values greater than one indicating that rainfall is distributed towards the catchment headwaters.

The second scaled moment $\delta_{2}(-)$ describes the dispersion of the rainfall-weighted flow distances about their mean value with respect to the dispersion of the flow distances. 
Values of $\delta_{2}$ close to 1 reflect a uniform-like rainfall distribution, with values less than 1 indicating that rainfall is characterised by a unimodal distribution along the flow distance. As we will see below, values greater than 1 are generally rare, and indicate cases of multimodal rainfall distributions.

The spatial moments defined in Eq. (3) describe the instantaneous spatial rainfall organization at a certain time $t$. Equations (1) to (3) can also be used to describe the spatial rainfall organization corresponding to the cumulated rainfall over a certain time period $T_{\mathrm{s}}$ (e.g. a storm event). These statistics, which are obtained by integrating over time, are termed $P_{n}$ and $\Delta_{n}$. These statistics are defined as follows:

$P_{n}=|A|^{-1} \int_{A} r_{t}(x, y) d(x, y)^{n} d A=\frac{1}{T_{\mathrm{S}}} \int_{T_{\mathrm{S}}} p_{n}(t) d t$

where $r_{t}(x, y)$ is the mean value of time integrated rainfall at location $(x, y) . \quad \Delta_{1}$ and $\Delta_{2}$ are computed based on $P_{n}$ following Eq. (3), as follows

$$
\begin{aligned}
& \Delta_{1}=\frac{P_{1}}{P_{0} g_{1}} \\
& \Delta_{2}=\frac{1}{g_{2}-g_{1}^{2}}\left[\frac{P_{2}}{P_{0}}-\left(\frac{P_{1}}{P_{0}}\right)^{2}\right]
\end{aligned}
$$

The distance from the rainfall centroid to the catchment outlet is represented by the product $\delta_{1} g_{1}$. Interestingly, the analysis of the evolution in time of this distance enables the calculation of an instantaneous catchment-scale storm velocity along the river network, as follows:

$$
V_{\mathrm{s}}(t)=g_{1} \frac{d}{d t} \delta_{1}(t)
$$

Positive values of the storm velocity $V_{\mathrm{s}}\left(\mathrm{L} \mathrm{T}^{-1}\right)$ correspond to upbasin storm movement, whereas downbasin storm movement are related to negative values of $V_{\mathrm{s}}$. The concept of the catchment-scale storm velocity defined by Eq. (6) takes into account the role of relative catchment orientation and morphology with respect to storm motion and kinematics. For instance, for the same storm kinematics, the same elongated basin will be subject to different catchment scale storm velocities by varying its orientation with respect to that of the storm motion. In this work, we will not perform any explicit derivative of $\delta_{1}$ to obtain the catchment scale storm velocity. Equation (6) has been introduced only to formally represent the concept of storm velocity and how this relates to the first scaled moment $\delta_{1}$. A simple way to derive the mean value of $V_{\mathrm{s}}$, derived from the methodology introduced by Viglione et al. (2010a), is reported in the next sections.

\section{Relationship between the spatial moments of catchment rainfall and the shape of the flood response}

Viglione et al. (2010a) proposed an analytical framework (called V2010 hereafter) for quantifying the effects of spacetime variability on catchment flood response. Viglione et al. (2010a) extended the analytical framework developed in Woods and Sivapalan (1999) to characterize flood response in the case where complex space and time variability of both rainfall and runoff generation are considered as well as hillslope and channel network routing.

In the V2010 methodology, the rainfall excess $r_{\mathrm{e}}(x, y, t)$ $\left(\mathrm{L} \mathrm{T}^{-1}\right)$ at a point $(x, y)$ and at time $t$ generated by precipitation $r(x, y, t)$ is given by

$r_{\mathrm{e}}(x, y, t)=r(x, y, t) \cdot c(x, y, t)$

where $c(x, y, t)(-)$ is the local runoff coefficient, bounded between 0 and 1 . V2010 characterizes the flood response with three quantities: (i) the catchment- and storm-averaged value of rainfall excess, (ii) the mean runoff time (i.e. the time of the center of mass of the runoff hydrograph at a catchment outlet), and (iii) the variance of the runoff time (i.e. the temporal dispersion of the runoff hydrograph). The mean time of catchment runoff is a surrogate for the time to peak. The variance of runoff time is indicative of the magnitude of the peak runoff. For a given event duration and volume of runoff, a sharply peaked hydrograph will have a relatively low variance compared to a more gradually varying hydrograph (see Woods, 1997, for details).

Since the aim of this study is to establish a relationship between the spatial moments of catchment rainfall and the flood response shape, we modified accordingly the V2010 methodology by assuming that the runoff coefficient is uniform in space and time, and that the hillslope residence time is negligible. Hence, in the following developments the rainfall intensity and accumulation are used in place of the rainfall excess. Owing to this assumption, results obtained by this approach are likely to apply to heavy rainfall events characterized by large rain rates and accumulations. The runoff transport is described by using an advection velocity $v\left(\mathrm{~L} \mathrm{~T}^{-1}\right)$ which is considered invariant in space and time. The hypothesis of spatially uniform flow velocity is consistent with the results of previous studies, showing that it is always possible to find a single value of flow celerity $v$ such as the mean travel time across the entire catchment and therefore the catchment response time is unchanged (Robinson et al., 1995; Saco and Kumar, 2002; D'Odorico and Rigon, 2003).

The analytical results are summarized below, by focusing on the elements which are essential to derive the relationship between the spatial moments and the characteristics of the flood response shape, i.e. the mean and the variance of runoff time and the catchment scale storm velocity. Catchment runoff time is treated as a random variable (denoted $T_{\mathrm{q}}$ ), which measures the time from the storm beginning until a 
drop of water exits the catchment. Water that passes a catchment outlet goes through two successive stages in our conceptualisation: (i) the generation of runoff at a point (including waiting for the rain to fall), (ii) runoff transport. Each of these stages has an associated "holding time", which is conveniently treated as a random variable (e.g. Rodriguez-Iturbe and Valdes, 1979). Since the water exiting the catchment has passed in sequence through the two stages mentioned above we can write

$T_{\mathrm{q}}=T_{\mathrm{r}}+T_{\mathrm{c}}$

where $T_{\mathrm{r}}$ and $T_{\mathrm{c}}$ are the holding times for rainfall excess and runoff transport.

Mean catchment runoff time. Using the mass conservation property (see V2010) we can write the mean of $T_{\mathrm{q}}$ as

$E\left(T_{\mathrm{q}}\right)=E\left(T_{\mathrm{r}}\right)+E\left(T_{\mathrm{c}}\right)$

The first term $E\left(T_{\mathrm{r}}\right)$ represents the time from the start of the event to the centroid of the rainfall time series, and is independent from the rainfall spatial variability. For the conceptualization of $E\left(T_{\mathrm{r}}\right)$, which is not of interest here, we refer to V2010. The second term $E\left(T_{\mathrm{c}}\right)$ represents the average time to route the rainfall excess from the geographical centroid of the rainfall spatial pattern to the catchment outlet. By using the spatial moments, the term $E\left(T_{\mathrm{c}}\right)$ may be expressed as follows:

$$
\begin{aligned}
E\left(T_{\mathrm{c}}\right) & =\frac{\int_{0}^{T_{\mathrm{s}}}\left[\int_{0}^{A} r(x, y, t) d(x, y) d A\right] d t}{A T_{\mathrm{S}} P_{0} v} \\
& =\frac{P_{1}}{P_{0} v}=\Delta_{1} g_{1} \frac{1}{v}
\end{aligned}
$$

where $T_{\mathrm{s}}$ is the duration of the storm event.

Therefore, Eq. (8) may be written as follows:

$$
E\left(T_{\mathrm{q}}\right)=E\left(T_{\mathrm{r}}\right)+\frac{\Delta_{1} g_{1}}{v}
$$

Details concerning the derivation of Eq. (10) based on V2010 are reported in the Appendix. It is important to note here that the spatial distribution of the rainfall excess is the same as that of the rainfall pattern, since the runoff coefficient is assumed to be spatially uniform.

It is interesting to note that, from Eq. (10), the first timeintegrated scaled moment represents the ratio between the routing time corresponding to the rainfall center of mass with respect to the catchment response time $g_{1} / v$ :

$$
\Delta_{1}=\frac{E\left(T_{\mathrm{c}}\right)}{\frac{g_{1}}{v}}
$$

Analogously to $\delta_{1}$, the values of $\Delta_{1}$ are greater than zero, and are equal to one for the case of spatially uniform precipitation or for a spatially variable precipitation which is concentrated on the catchment centroid. Values of $\Delta_{1}$ less than one indicate that rainfall is concentrated towards the outlet, and values larger than one indicate that rainfall is concentrated towards the headwater portion of the basin. Based on Eq. (10), the statistic $\Delta_{1}$ measures the hydrograph timing shift relative to the position of the rainfall centroid over the catchment. As it will be shown later in the paper, the statistic $\Delta_{1}$ is related to the normalised mean time difference between the hydrograph obtained by considering the actual rainfall pattern and the hydrograph resulting from a spatially uniform rainfall pattern (all other factors being taken equal). The normalising quantity is given by the response time of the catchment. The effect of a less-than-one value of $\Delta_{1}$ indicates an anticipation of the mean hydrograph time with respect to the case of spatially uniform precipitation. The opposite holds true for the case of a larger-than-one value of the statistic. As an example, this means that a value of $\Delta_{1}$ equal to 1.5 indicates that the mean time difference between the two hydrographs corresponds to half the catchment response time, with the hydrograph obtained from the spatially distributed rainfall delayed with respect to the one obtained from uniform rainfall. A value of $\Delta_{1}$ equal to 0.5 indicates the same normalized mean difference, but with the opposite sign (the hydrograph obtained from the spatially distributed rainfall is anticipated with respect to the one obtained from uniform rainfall).

One should note that the storm velocity has no influence on $E\left(T_{\mathrm{q}}\right)$. This is a direct consequence of the hypotheses used to derive the statistics. The catchment response is described as fully kinematic, therefore it is influenced by the averaged spatial organization of the rainfall and not by the variability of the spatial organization within the storm, and the routing is linear.

Variance of catchment runoff time. The variance of $T_{\mathrm{q}}$, which represents the dispersion of the hydrograph, is given by

$\operatorname{Var}\left(T_{\mathrm{q}}\right)=\operatorname{Var}\left(T_{\mathrm{r}}\right)+\operatorname{Var}\left(T_{c}\right)+2 \operatorname{Cov}\left(T_{\mathrm{r}}, T_{\mathrm{c}}\right)$

We focus here on the terms $\operatorname{Var}\left(T_{\mathrm{c}}\right)$ and $2 \operatorname{Cov}\left(T_{\mathrm{r}}, T_{\mathrm{c}}\right)$. For the conceptualization of $\operatorname{Var}\left(T_{\mathrm{r}}\right)$, which is not of interest here, we refer to V2010.

By using the concept of scaled spatial moments, $\operatorname{Var}\left(T_{\mathrm{c}}\right)$ may be written as follows.

$\operatorname{Var}\left(T_{\mathrm{c}}\right)=\frac{\Delta_{2}}{v^{2}}\left(g_{2}-g_{1}^{2}\right)$

Details concerning the derivation of Eq. (13) are reported in the Appendix, based on V2010. For the case of $\operatorname{Cov}\left(T_{\mathrm{r}}, T_{\mathrm{c}}\right)$ equal to zero, $\Delta_{2}$ represents the ratio between the differential variance in runoff timing generated by rainfall spatial distribution, and the variance of the catchment response time. The values of $\Delta_{2}$ are greater than zero and take the value of one when the rainfall field is spatially uniform. When the rainfall field is spatially concentrated anywhere in the basin, the values of $\Delta_{2}$ are less than one. In the less frequent cases when the rainfall field has a bimodal spatial distribution, with concentration both at the headwaters and at the outlet of the 
catchment, the values of $\Delta_{2}$ are greater than one. It should be noted that, with the rainfall excess volume remaining unchanged, the effect of decreasing the variance of runoff time is to increase the flood peak. This shows that in general the parameter $\Delta_{1}$ is expected to have an influence on the runoff timing, whereas the parameter $\Delta_{2}$ should affect the shape of the hydrograph and then the value of the flood peak.

As discussed in V2010, Eq. (25), the role of catchment scale storm velocity is represented by the term $\operatorname{Cov}\left(T_{\mathrm{r}}, T_{\mathrm{c}}\right)$. By using rainfall weights, defined as

$w(t)=\frac{p_{0}(t)}{P_{0}}$

and based on V2010 (see Appendix for the details of the derivation), the term $\operatorname{Cov}\left(T_{\mathrm{r}}, T_{\mathrm{c}}\right)$ in Eq. (12) may be written as follows:

$$
\operatorname{Cov}\left(T_{\mathrm{r}}, T_{\mathrm{c}}\right)=g_{1}\{\underbrace{\frac{\operatorname{Cov}_{t}\left[T, \delta_{1}(t) w(t)\right]}{v}}_{\text {term } 1}-\underbrace{\frac{\operatorname{Cov}_{t}[T, w(t)]}{v}}_{\text {term } 2} \Delta_{1}\}
$$

where $\operatorname{Cov}_{t}[]$ is the temporal covariance of the spaceaveraged terms. Here we define the term "catchment scale storm velocity" $V_{\mathrm{s}}$ as follows

$$
V_{\mathrm{S}}(t)=\underbrace{g_{1} \frac{\operatorname{Cov}_{t}\left[T, \delta_{1}(t) w(t)\right]}{\operatorname{var}[T]}}_{V_{\mathrm{s} 1}}-\underbrace{g_{1} \frac{\operatorname{Cov}_{t}[T, w(t)]}{\operatorname{var}[T]} \Delta_{1}}_{V_{\mathrm{s} 2}}
$$

where the two velocity terms $V_{\mathrm{s} 1}$ and $V_{\mathrm{s} 2}$ correspond to the groups term ${ }_{1}$ and term 2 in Eq. (15). It is worth recognizing that the groups term 1 and term 2 represent the slope coefficients of linear space-time regressions. Term 1 is the slope coefficient of the regression of the product $\delta_{1}(t) w(t)$ with time; term ${ }_{2}$ is the slope coefficient of the regression of the weights $w(t)$ with time.

Equation (16) shows that the velocity formulation is given by the difference between two velocity terms. The first term describes the total storm motion, as related to the temporal evolution of the product of the weights of the precipitation $w(t)$ and of the centroid $\delta_{1}(t)$. The second term describes the temporal storm variability, as it is summarized by the temporal evolution of the precipitation weights. Some examples may help understand the concept of storm velocity in idealized cases. For the case of temporally uniform mean areal rainfall, $w(t)$ is constant, $V_{\mathrm{s} 2}$ is equal to zero, and the value of $V_{\mathrm{s}}$ depends only on the evolution in time of the position of the rainfall centroid along the flow distance coordinate $\left(V_{\mathrm{s} 1}\right)$. Conversely, if there is only temporal variation of the mean areal rainfall and $\delta_{1}(t)$ is constant, the two velocity terms $V_{\mathrm{s} 1}$ and $V_{\mathrm{s} 2}$ will be equal in value and opposite in sign, implying that $V_{\mathrm{s}}$ will be equal to zero. Note that the sign of the velocity is positive (negative) for the case of upstream (downstream) storm motion.

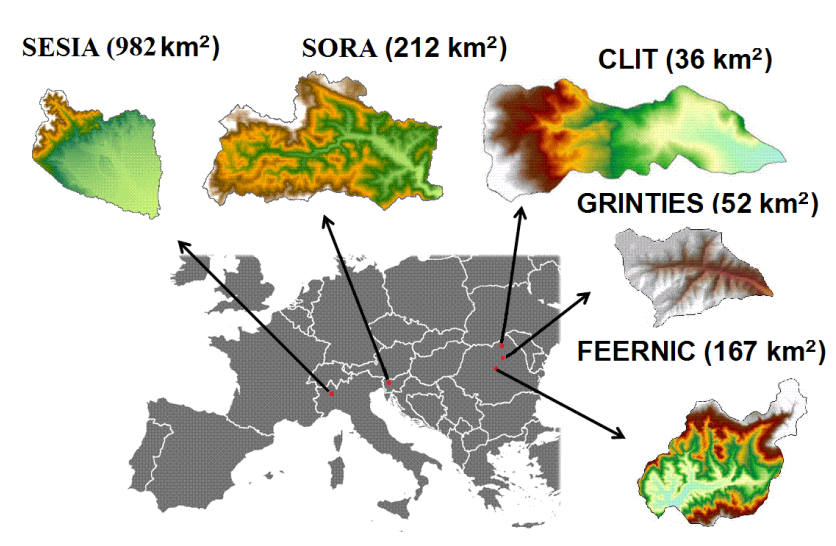

Fig. 1. Study catchments and their location in Europe.

Finally, the term $\operatorname{Cov}\left(T_{\mathrm{r}}, T_{\mathrm{c}}\right)$ may be written as follows:

$$
\operatorname{Cov}\left(T_{\mathrm{r}}, T_{\mathrm{c}}\right)=g_{1}\{\underbrace{\frac{\operatorname{Cov}_{t}\left[T, \delta_{1}(t) w(t)\right]}{v}}_{\text {term } 1}-\underbrace{\frac{\operatorname{Cov}_{t}[T, w(t)]}{v}}_{\text {term } 2} \Delta_{1}\}
$$

As a result, for downstream moving storm the variance of catchment runoff time tends to reduce and therefore the peak discharge tends to increase, consistently with the findings from several investigations (Niemczynowicz, 1984; Ogden et al., 1995; De Lima and Singh, 2002). The opposite occurs with upstream moving storms, which tend to increase the hydrograph time variance and hence to reduce the peak discharge.

\section{Assessment of spatial moments of catchment rainfall}

Assessment of spatial moments of catchment rainfall is reported for five extreme storms and ensuing floods which have been observed in Europe in the period between 2002 and 2007 (Fig. 1). The case studies are the following: Sesia at Quinto (North-western Italy, $982 \mathrm{~km}^{2}$ ) occurred on 4 July 2002, Sora at Vester (Slovenia, $212 \mathrm{~km}^{2}$ ), occurred on 18 September 2007, Feernic at Simonesti (Romania, $168 \mathrm{~km}^{2}$ ), occurred on 23 August 2005, Clit at Arbore (Romania, $36 \mathrm{~km}^{2}$ ), occurred on 30 June 2006 and Grinties at Grinties (Romania, $51 \mathrm{~km}^{2}$ ), occurred on $4 \mathrm{Au}$ gust 2007. The main features of the storms and ensuing floods are reported in Table 1. These storms were selected because of the various catchment sizes (ranging from 36 to $982 \mathrm{~km}^{2}$ ), storm durations (ranging from $5 \mathrm{~h} 30 \mathrm{~min}$ to $21 \mathrm{~h}$ ) and space-time variability which characterize the storm events. The data concerning the events were derived from the flash flood data archive developed in the frame of the EU Project HYDRATE (www.hydrate.tesaf.unipd.it) (Borga et al., 2010). The archive includes data from twenty-five major flash flood events that occurred in various regions of 
Europe since 1994, with twenty events occurred since 2000. The hydro-meteorological data includes high-resolution rainfall patterns, flow type processes (either liquid flow or debris flow or hyperconcentrated flows) and hydrographs or peak discharges. Climatic information and data concerning morphology, land use and geology are also included in the database. These data enable the identification and analysis of the hydrometeorological causative processes and the individual reconstruction of the events by using hydrologic and hydraulic modelling.

For the five events, both original raw radar reflectivity values and raingauge data were made available for rainfall estimation. The quantitative precipitation estimation problem is particularly crucial and difficult in the context of flash-floods since the causative rain events may develop at very short space and time scales (Krajewski and Smith 2002; Bouilloud et al., 2010). The methodology implemented here for radar rainfall estimation is based on the application of correction procedures exploiting the understanding of radar observation physics. It is based on (1) detailed collection of data and metadata about the radar systems and the raingauge networks (including raingauge data from amateurs and from bucket analysis), (2) analysis of the detection domain and the ground/anthropic clutter for the considered case (Pellarin et al., 2002), (3) implementation of corrections for rangedependent errors (e.g. screening, attenuation, vertical profiles of reflectivity) and (4) optimisation of the rainfall estimation procedure by means of radar-raingauge comparisons at the event duration scale (Buoilloud et al., 2010). The methodology was applied consistently in the same form over the five storm events.

Analyses of rainfall variability by means of the spatial moments is attempted here to isolate and describe the features of rainfall spatial organisation which have significant impact on runoff simulation. As such, spatial moments provide information to quantify hydrological similarities among different storms, and support the transfer of knowledge and exchange of estimation and analysis techniques. The rainfall spatial moments and the catchment-scale storm velocity were computed at each time step (either at 15-min or 30-min time steps) as time series, to examine the variability in time of the statistics. The time series of the first and second scaled moments of catchment rainfall are reported in Plates 1 and 2, together with the basin-averaged rainfall rate, the fractional coverage of the basin by rainfall rates exceeding $20 \mathrm{~mm} \mathrm{~h}^{-1}$ (this threshold has been selected to indicate a flood-producing rainfall intensity), and the storm velocity. The values of catchment scale storm velocity were computed by applying Eq. (16). The two velocity terms $V_{\mathrm{s} 1}$ and $V_{\mathrm{s} 2}$ were computed by assessing the slope of the corresponding linear regressions, by using a moving window with window size equal to the catchment response time.

The time series of the first scaled spatial moment $\delta_{1}$ exhibit a relatively large variability, particularly in the Feernic case, with the first scaled moments varying from 0.6 to 1.6 in the first 80 min (with a clear upbasin storm motion, as reflected in the increasing values of the statistic) and then decreasing in the following three hours, where a downbasin storm motion can be recognized. A strong downbasin storm motion can be recognized even for the Grinties during the period of strong flood-producing rainfall, with values of $\delta_{1}$ steadily decreasing from 1.2 to 0.7 . The case of the Sesia river basin at Quinto, as well as that of Feernic, documents the striking effect of the orography on convection development, with a concentration of the flood producing rainfall on the headwaters and values of $\delta_{1}$ ranging between 1.4 and 1.6 during the period of flood-producing rainfall. Examination of the values reported for Grinties shows that the spatial moments may take values quite far from one even in small basins. The values of $\delta_{2}$ generally reflects the trend of $\delta_{1}$, as expected, with small values of dispersion when $\delta_{1}$ is both larger or smaller than one, and values of dispersion close to one when $\delta_{1}$ is also close to unity.

For three cases out of the five (Grinties, Sora and Sesia), the values of the catchment scale storm velocity are significantly different from zero. For the case of Grinties, the value of storm velocity is steadily around $-0.2 \mathrm{~m} \mathrm{~s}^{-1}$ for the period of strong rain rates, reflecting the important downbasin motion reported for the rainfall center of mass. A similar velocity $\left(-0.3 \mathrm{~m} \mathrm{~s}^{-1}\right)$ is found for the event occurred on the Sora. An upbasin storm velocity value ranging between 0.3 and $0.4 \mathrm{~m} \mathrm{~s}^{-1}$ is reported for the case of Sesia at Quinto. This value is clearly consistent with the constant upflow of humid air that sustained the formation of convective cells over the steep topography of the basin. In the three cases, the values of the storm velocity are relatively small with respect to the flood flows celerity characterizing flash floods, which was quantified around to $3 \mathrm{~m} \mathrm{~s}^{-1}$ by Marchi et al. (2010) with reference to several flash floods in Europe. Previous work on the impact of storm velocity on hydrograph shape (Ogden et al., 1995) has shown that the effect of storm velocity is important when its magnitude become comparable to that of flood flow celerity. The significant differences between storm velocity and flood flows celerity suggests that even for these cases the values of storm velocity may be not large enough to influence the flood hydrograph shape. As a further step of the analysis, we examined the relationship between the statistics $\Delta_{1}$ and $\Delta_{2}$ (Fig. 2). The analysis is carried out by dissecting the five study catchments into a number of nested subcatchments (see Table 2), as a means to examine potential catchment scale effects on the relationship between $\Delta_{1}$ and $\Delta_{2}$. The subdivision into subcatchments was either based on earlier hydrological analyses (see Table 1) where post-flood observations were used to derive indirect peak discharges (Borga et al., 2008) or on availability of internal streamgauges. Details are reported in the papers describing the relevant case studies (Sangati et al., 2009; Zoccatelli et al., 2010; Zanon et al., 2010). This subdivision will be used also for the hydrological simulations in Sect. 5. Overall, 27 catchments were used for the computation of $\Delta_{1}$ and $\Delta_{2}$. The corresponding 

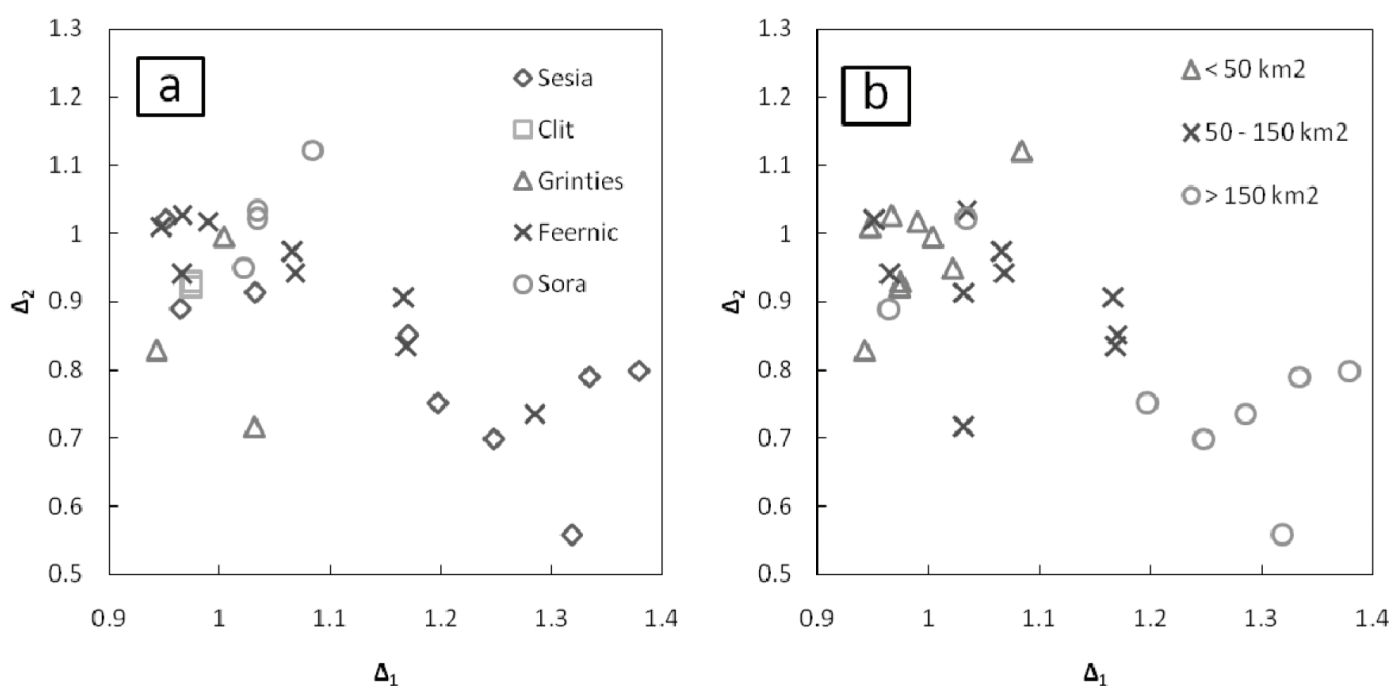

Fig. 2. Relationship between $\Delta_{1}$ and $\Delta_{2}$ : (a) for the study catchments, (b) for specific classes of catchment area.

Table 1. Flood cases considered in the study.

\begin{tabular}{llcccccc}
\hline Event & Date & $\begin{array}{c}\text { Rainfall } \\
\text { aggregation time }\end{array}$ & $\begin{array}{c}\text { Area } \\
\left(\mathrm{km}^{2}\right)\end{array}$ & $\begin{array}{c}\text { Duration } \\
(\mathrm{hh:mm})\end{array}$ & $\begin{array}{c}\text { Rain cum. } \\
(\mathrm{mm})\end{array}$ & $\begin{array}{c}\text { Peak flow } \\
\left(\mathrm{m}^{3} \mathrm{~s}^{-1}\right)\end{array}$ & References \\
\hline Sesia at Quinto & $04 / 06 / 2002$ & $30^{\prime}$ & 982 & $21: 30$ & 111 & 1358 & Sangati et al. (2009) \\
Feernic at Simonesti & $23 / 08 / 2005$ & $15^{\prime}$ & 167 & $5: 30$ & 76 & 357 & Zoccatelli et al. (2010) \\
Clit at Arbore & $30 / 06 / 2006$ & $15^{\prime}$ & 36 & $7: 00$ & 81 & 156 & Zoccatelli et al. (2010) \\
Grinties at Grinties & $04 / 08 / 2007$ & $15^{\prime}$ & 52 & $7: 00$ & 67 & 89.5 & Zoccatelli et al. (2010) \\
Sora at Vester & $18 / 09 / 2007$ & $30^{\prime}$ & 212 & $17: 45$ & 157 & 384 & Zanon et al. (2010) \\
\hline
\end{tabular}

Table 2. Number and area ranges of sub-basins examined in each case study.

\begin{tabular}{lccc}
\hline Event & Date & $\begin{array}{c}\text { Number of } \\
\text { sub-basins }\end{array}$ & $\begin{array}{c}\text { Range of } \\
\text { sub-basin areas }\end{array}$ \\
\hline Sesia at Quinto & $04 / 06 / 2002$ & 9 & $75-982$ \\
Feernic at Simonesti & $23 / 08 / 2005$ & 9 & $5-167$ \\
Clit at Arbore & $30 / 06 / 2006$ & 2 & $12-36$ \\
Grinties at Grinties & $04 / 08 / 2007$ & 3 & $11-52$ \\
Sora at Vester & $18 / 09 / 2007$ & 4 & $32-212$ \\
\hline
\end{tabular}

catchment size ranges between 5 and $982 \mathrm{~km}^{2}$, with 9 catchments less than $50 \mathrm{~km}^{2}, 10$ catchments ranging between 50 and $150 \mathrm{~km}^{2}$, and 8 catchments larger than $150 \mathrm{~km}^{2}$.

Inspection of this figure shows that in 16 cases out of 27 the value of $\Delta_{1}$ falls in a narrow interval around one $\left(0.95<\Delta_{1}<1.07\right)$. In 13 cases out of these 16 cases, $\Delta_{2}$ ranges between 0.9 and 1.02, indicating that generally $\Delta_{2}$ is close to one when $\Delta_{1}$ is also close to one. In these cases the first two scaled moments are virtually unchanged with respect to the spatially uniform rainfall case. However, it is interesting to note one case of Grinties, reporting a value of $\Delta_{2}$ around 0.7 in correspondence to a value of $\Delta_{1}$ equal to 1.03. This is one of the few cases in which a strong rainfall concentration corresponds spatially to the geomorphologic center of mass of the catchment. When $\Delta_{1}$ exceeds the upper bound of the interval (1.07), the corresponding value of $\Delta_{2}$ is lower than 0.9 . There is only one case of $\Delta_{2}$ exceeding 1.1 , indicating a case of multimodal spatial distribution of rainfall. More than half of the cases show values of $\Delta_{1}$ in the range 1.05-1.4, documenting the effect of orography on the spatial rainfall distribution. Indeed, one of the elements that favour the anchoring of convective system is the orography, which play an important role in regulating of atmospheric moisture inflow to the storm and in controlling storm motion and evolution (Davolio et al., 2006). Consistently with this observation, values of $\Delta_{1}$ less than 0.95 are not represented in the study floods.

As expected, all but two of the catchments with area less than $50 \mathrm{~km}^{2}$ are characterized by values of $\Delta_{1}$ and $\Delta_{2}$ close to one. For these cases, we expect a limited impact of rainfall spatial organization on flood response. On the other side, six out of the eight cases with catchment area exceeding $150 \mathrm{~km}^{2}$ 


\section{Feernic at Simonesti $\left[166.7 \mathrm{~km}^{2}\right]$}
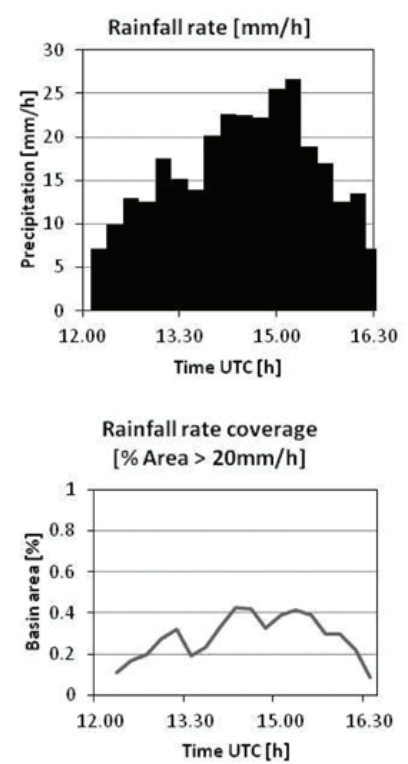

$\delta_{1}$

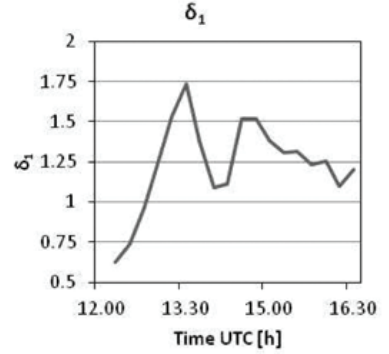

$\delta_{2}$
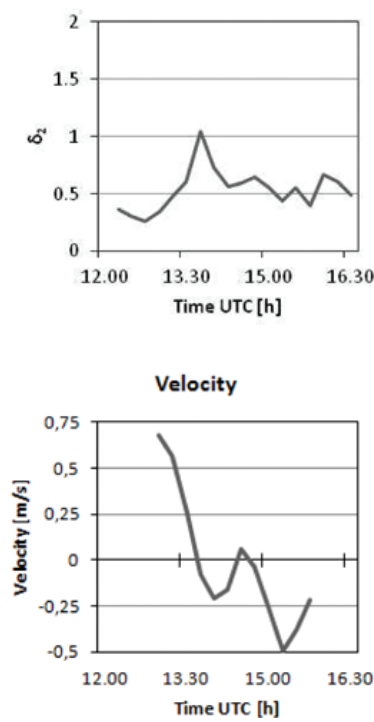

Clit at Arbore $\left[36 \mathrm{~km}^{2}\right]$

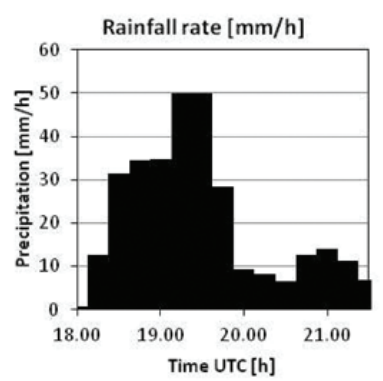

Rainfall rate coverage

[\% Area $>20 \mathrm{~mm} / \mathrm{h}$ ]

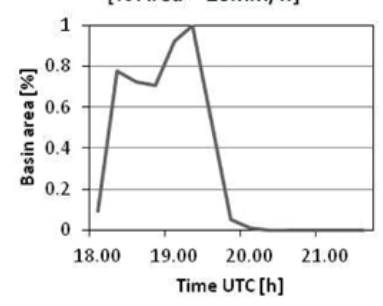

$\delta_{1}$

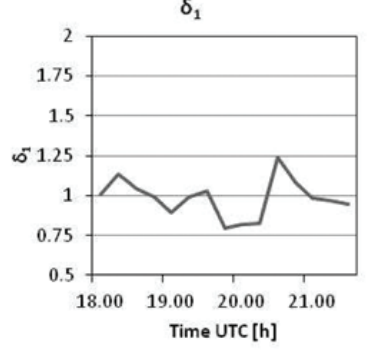

$\delta_{2}$
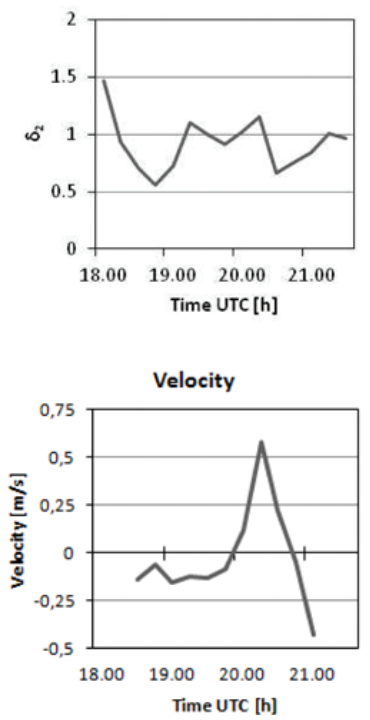

Grinties at Grinties $\left[52 \mathbf{~ k m}^{2}\right]$

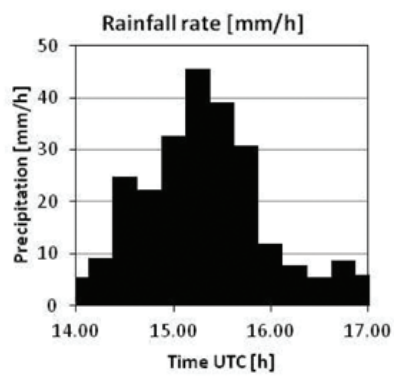

Rainfall rate coverage $[\%$ Area $>20 \mathrm{~mm} / \mathrm{h}$ ]

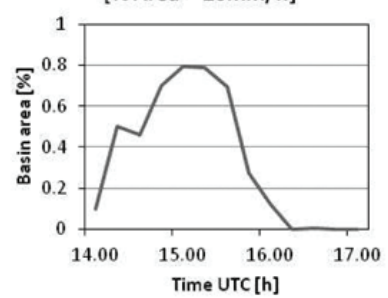

$\delta_{1}$

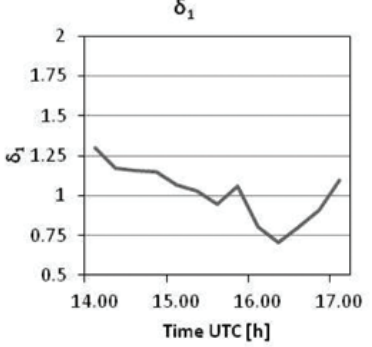

$\delta_{2}$
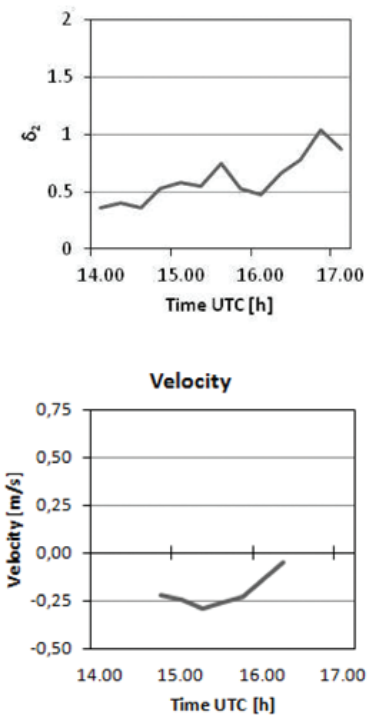

Plate 1. Precipitation analyses by using time series of precipitation intensity, coverage (for precipitation intensity $>20 \mathrm{~mm} \mathrm{~h}^{-1}$ ), $\delta_{1}(-), \delta_{2}(-)$ and storm velocity for Feernic, Clit and Grinties. 


\section{Sora at Vester $\left[212 \mathrm{~km}^{2}\right]$}
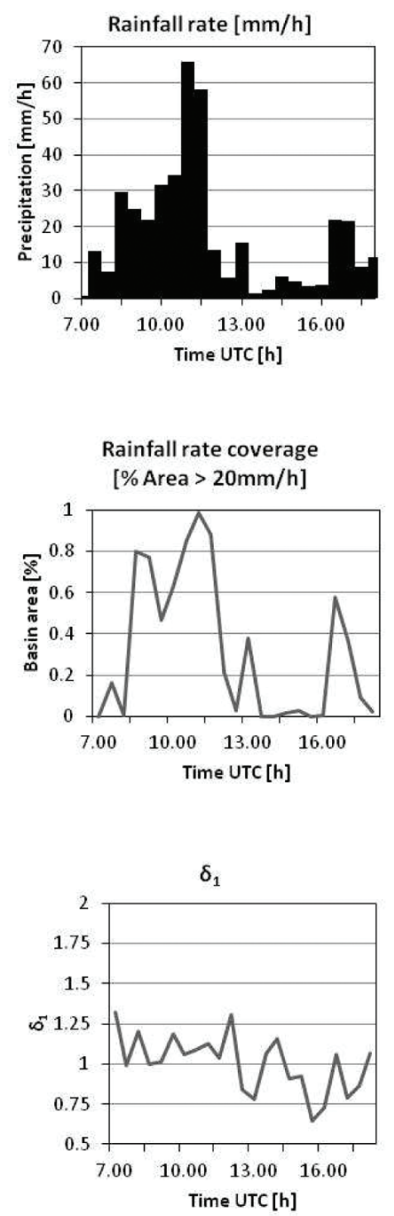

$\delta_{2}$
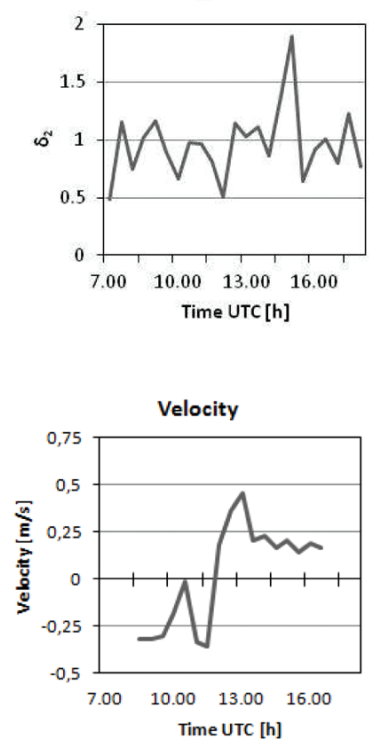

Sesia at Quinto $\left[982 \mathrm{~km}^{2}\right]$
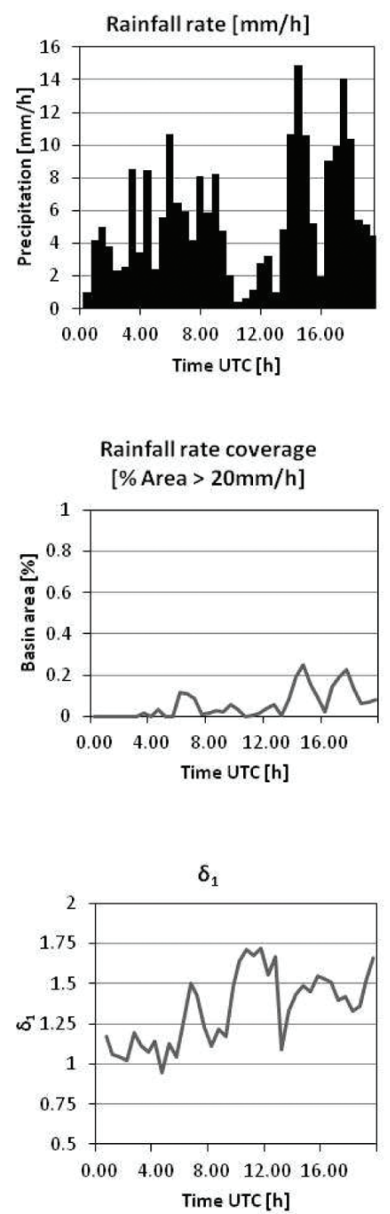

$\delta_{2}$
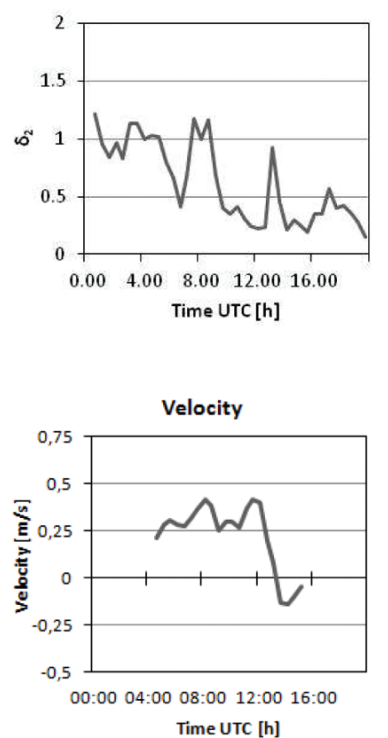

Plate 2. Precipitation analyses by using time series of precipitation intensity, coverage (for precipitation intensity $\left.>20 \mathrm{~mm} \mathrm{~h}^{-1}\right), \delta_{1}(-), \delta_{2}(-)$ and storm velocity for Sora and Sesia. 
are characterized by values of $\Delta_{1}$ larger than 1.2 and corresponding values of $\Delta_{2}$ less than 0.8 . These values (corresponding to subcatchments of Sesia and Feernic) imply a strong concentration of rainfall towards headwater and a correspondingly low dispersion around the mean values. Accordingly with the analysis reported in this work, these characteristics should translate to a delayed and more peaky hydrograph, with respect to the one obtained by using spatially uniform rainfall.

\section{Examination of runoff model sensitivity to rainfall spatial organization by using scaled spatial moments of catchment rainfall: the case of the timing error}

In this section we quantify the effect of neglecting the rainfall spatial variability on the rainfall-runoff model application. Hydrologic response from the five storm events over the 27 subcatchments analysed in Sect. 4 is examined by using a simple spatially distributed hydrologic model. The distributed model is based on availability of raster information of the landscape topography and of the soil and land use properties. In the model, the runoff rate $q(x, y, t)\left(\mathrm{L} \mathrm{T}^{-1}\right)$ at time $t$ and location $x, y$ is computed from the rainfall rate $r(x, y, t)\left(\mathrm{L} \mathrm{T}^{-1}\right)$ using the Green-Ampt infiltration model with moisture redistribution (Ogden and Saghafian, 1997). The adopted formulation of the Green and Ampt model has been chosen because it provides a simple, but not simplistic (Barry et al., 2005) and yet physically-based description of the infiltration-excess mechanisms. A simple description of the drainage system response (Da Ros and Borga, 1997) is used to represent runoff propagation. The distributed runoff propagation procedure is based on the identification of drainage paths, and requires the characterization of hillslope paths and channeled paths. A channelization support area $\left(A_{\mathrm{s}}\right)\left(\mathrm{L}^{2}\right)$ is used to distinguish hillslope elements from channel elements. The model includes also a linear conceptual reservoir for base flow modeling (Zoccatelli et al., 2010). The reservoir input is provided by the infiltrated rate computed based on the Green-Ampt method. The model parameters were estimated over the catchments available for each event by means of a combination of manual and automatic calibration to minimize either the Nash-Sutcliffe efficiency index over the flood hydrographs (for the gauged catchments) or the mean square error over the flood peak and the timing data (rise, peak and recession) (for catchments where runoff data were provided from post-event surveys). Details about the application of the model to the individual events, its calibration and its verification are reported in the relevant papers (Sangati et al., 2009; Zoccatelli et al., 2010; Zanon et al., 2010). In general, the model simulations of the flood hydrographs were closer to observations for the smaller basins where the linear routing approach implemented in the model provides a better description of the actual processes. In this first exploratory work we focus on the timing error (Ehret and Zehe, 2011), i.e. the difference in the timing of the centroid of the hydrographs obtained by using either spatially distributed or spatially uniform rainfall, and analyse the relationship between this kind of error and the $\Delta_{1}$ statistic. For each subcatchment, the flash flood response was simulated by using the actual rainfall spatial variability and then by using spatially uniform precipitations, hence obtaining two different hydrographs. Moreover, in order to clarify the relative roles of transport paths and of heterogeneity in the runoff generation processes, we performed numerical experiments in which the infiltration and the difference between hillslope and channel travel times are selectively "turned off", by assuming that the soil is impermeable and the hillslope and channel celerity have the same value.

The statistic $\Delta_{1}$ is expected to quantify the hydrograph timing error. For storms characterised by $\Delta_{1}$ larger than one, rainfall is concentrated towards the periphery of the catchment, with the hydrograph delayed relative to the case of a spatially uniform rainfall. The opposite is true for rainfall concentrated towards the outlet ( $\Delta_{1}$ less than one); in these cases the hydrograph should be anticipated relative to the case of spatially uniform rainfall. A statistic, termed "normalised time difference" $d T_{n}$, is introduced to quantify the timing error between the two hydrographs. The normalised time difference $d T_{n}$ is computed by dividing the time difference between the two hydrograph centroids by the response time of the catchment $E\left(T_{\mathrm{c}}\right)$, as follows:

$d T_{n}=\frac{E\left(T_{\mathrm{q}_{-} \text {Dist }}\right)-E\left(T_{\mathrm{q}_{-} \text {Unif }}\right)}{E\left(T_{\mathrm{c}}\right)}$

where $E\left(T_{\mathrm{q}-\text { Dist }}\right)$ and $E\left(T_{\mathrm{q}-\text { Unif }}\right)$ are the hydrograph centroids corresponding to the hydrographs generated by using spatially distributed rainfall (termed "reference hydrograph" hereinafter) and spatially uniform rainfall, respectively. A positive (negative) value of $d T_{n}$ implies a positive (negative) shift in time of the reference hydrograph with respect to the one produced by using uniform precipitation. It should be noted that Eq. (18) may written down by exploiting Eq. (10) as follows:

$$
\begin{aligned}
d T_{n} & =\frac{E\left(T_{\mathrm{q}_{-} \text {Dist }}\right)-E\left(T_{\mathrm{q}_{-} \text {Unif }}\right)}{E\left(T_{\mathrm{c}}\right)} \\
& =\frac{E\left(T_{\mathrm{r}}\right)+\frac{\Delta_{1} g_{1}}{v}-E\left(T_{\mathrm{r}}\right)-\frac{g_{1}}{v}}{\frac{g_{1}}{v}}=\Delta_{1}-1
\end{aligned}
$$

Equation (19) shows that the normalised timing error is related in a simple way to the spatial organisation of the rainfall fields by means of the scaled spatial moment of order one. The comparison between the two hydrographs is exemplified for the cases of Sesia at Quinto $\left(982 \mathrm{~km}^{2}\right)$ and of Grinties at Grinties $\left(52 \mathrm{~km}^{2}\right)$ in Fig. 3a and b, respectively. The storm event which triggered the Sesia flash flood was characterised by a strong concentration of rainfall towards the headwaters $\left(\Delta_{1}=1.33, \Delta_{2}=0.79\right)$, which implies a longer and more peaked catchment response with 

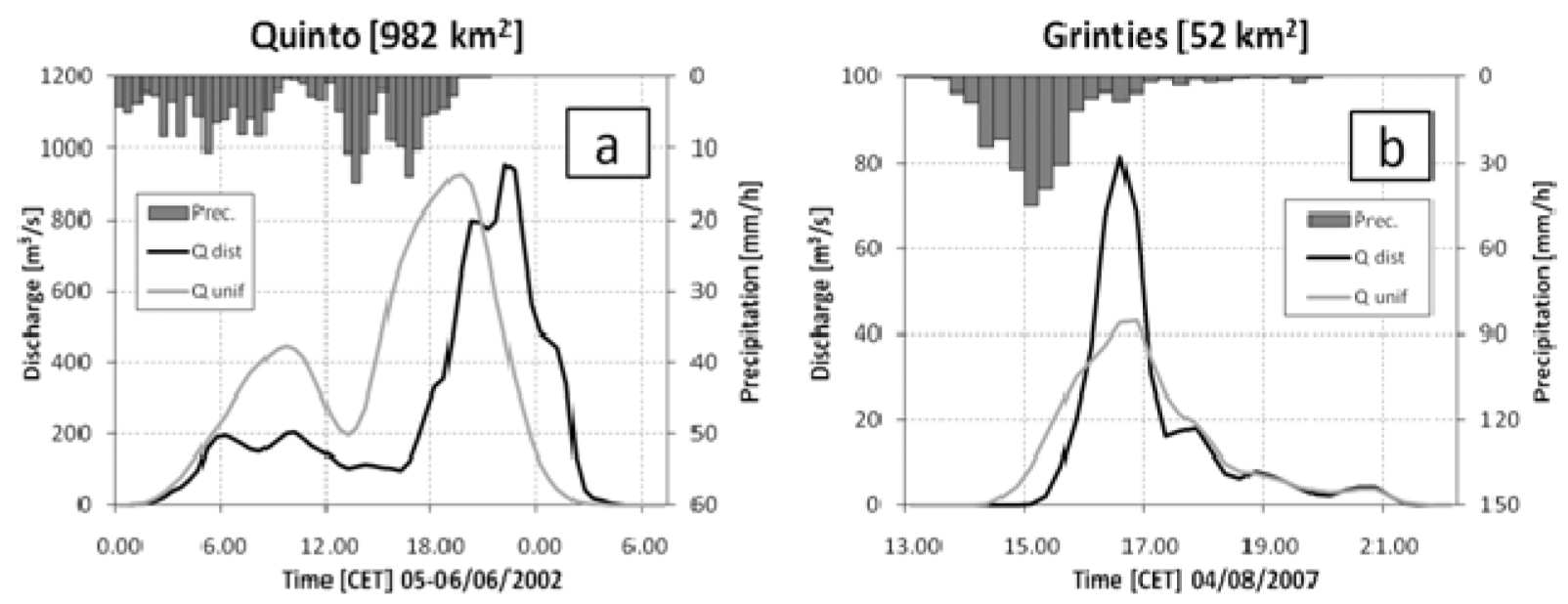

Fig. 3. (a, b): Modelled flood hydrographs obtained by using spatially distributed and uniform precipitation, for the case of (a) Sesia at Quinto $\left(982 \mathrm{~km}^{2}\right)$ and (b) Grinties at Grinties $\left(52 \mathrm{~km}^{2}\right)$.

respect to that corresponding to the case of spatially uniform precipitation. Correspondingly, the simulated flood peak obtained by using spatially uniform rainfall is too early $\left(d T_{n}=0.3\right)$ and its amplitude is too large with respect to the "reference" hydrograph. For the case of Grienties, the storm event was heavily concentrated over the catchment centroid $\left(\Delta_{1}=1.03, \Delta_{2}=0.72\right)$, which has no implications in terms of response timing $\left(d T_{n}=0.05\right)$ but translates to a much less peaked catchment response from spatially uniform rainfall with respect to the "reference". Both cases show clearly the impact of neglecting the spatial distribution of rainfall in rainfall-runoff modelling even at small and moderate catchment sizes.

To clarify the role of runoff transport processes alone on the sensitivity of runoff model to rainfall spatial organisation, we carried out three different sets of numerical experiments. In the first case, the soil is assumed everywhere completely impervious and the hillslope celerity has the same value as the channel celerity. The rainfall-runoff model in this case is subject to the same assumptions used to derive the spatial moments statistics. Results for the relationship between $d T_{n}$ and $\Delta_{1}$ for the various catchments are reported in Fig. 4a, whereas Fig. $4 \mathrm{~b}$ displays the same results for various classes of catchment size. The results show a linear relationship between the two variables, as expected. The linear regression is as follows

$d T_{n}=1.0014 \Delta_{1}-1.0019 ; \quad r^{2}=1$

which reproduces very well Eq. (19).

In the second case, the soils are again considered impervious, whereas the hillslopes and channels elements are considered separately, and are characterised by the celerities identified by means of the model calibration process. Results for the relationship between $d T_{n}$ and $\Delta_{1}$ for the various catchments are reported in Fig. 5a and b, showing again a strong linear relationship. The linear regression is as follows

$d T_{n}=0.72 \Delta_{1}-0.72 ; \quad r^{2}=0.99$

The introduction of the hillslope travel time leads to a decrease of the slope of the regression line, which decreases from 1.0 to 0.72 . This corresponds to a linear decrease of the timing error by $28 \%$, showing that the main effect of introducing the hillslope system is to decrease the influence of the rainfall spatial organisation on catchment response. It is likely that increasing the role of the hillslope residence time will further reduce the sensitivity of the hydrological model to rainfall spatial organization. The high determination coefficient of the regression line is a remarkable finding, since the hillslope travel times were calibrated individually to each flood event. This may suggest that the relative contribution of hillslopes and channels to the average residence time is rather similar through the various events. This is not surprising, given the extreme character of all the floods considered in this work.

In the third case, the model includes the actual distribution of the infiltration parameters and different celerities are used to simulate hillslopes and channels. The relationship between $d T_{n}$ and $\Delta_{1}$ is reported in Fig. 6a and b, whereas the linear regression is as follows

$d T_{n}=1.98 \Delta_{1}-2.07 ; \quad r^{2}=0.83$

The linear regression is characterized by a lower determination coefficient with respect to the previous cases. This reflects the specific features of each flood event. Results shown in Fig. 6 indicates the impact of rainfall spatial organization on flood modeling for small to moderate basin sizes. The timing error introduced by neglecting the rainfall spatial variability ranges between $-30 \%$ to $72 \%$ of the corresponding catchment response time. A feature worth noting in Fig. $6 \mathrm{a}$ 

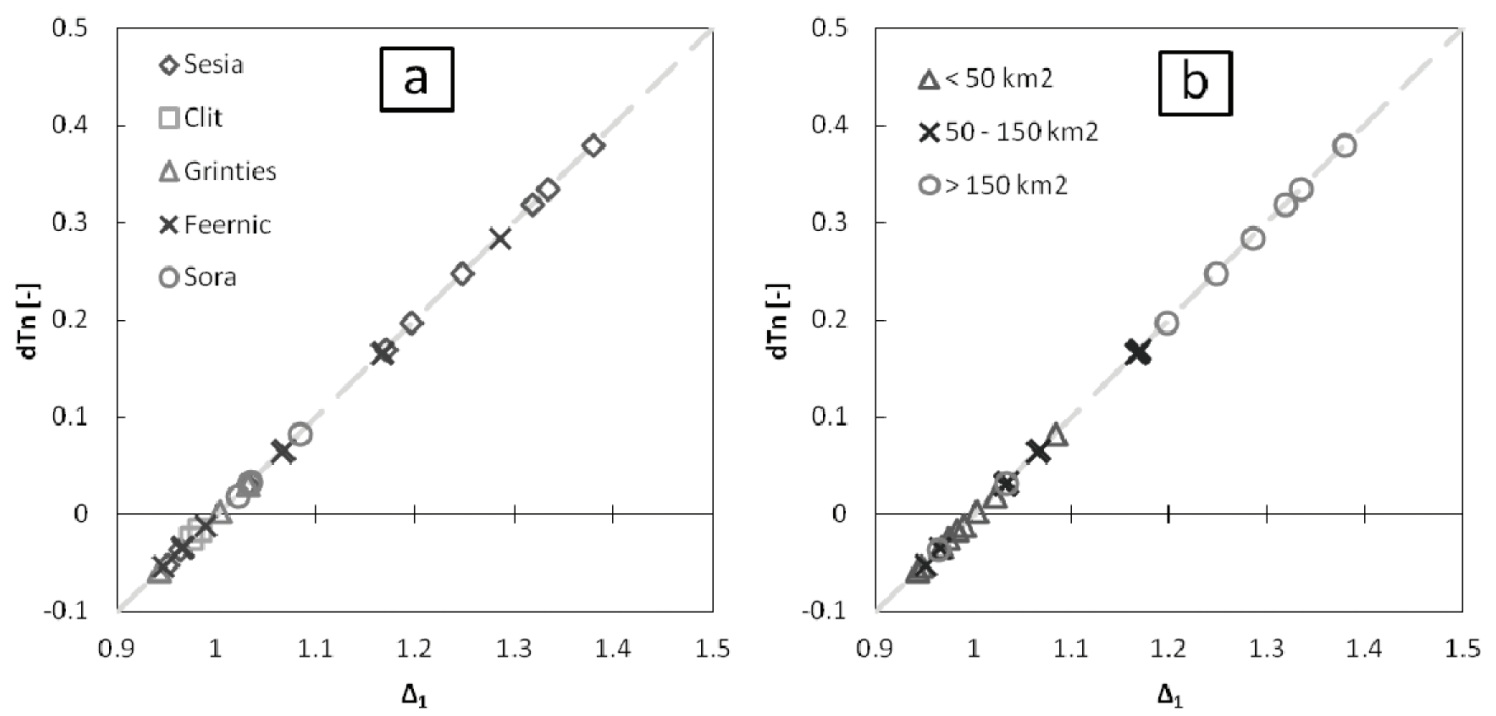

Fig. 4. (a, b): Relationship between $d T_{n}$ and $\Delta_{1}$ obtained by considering impervious soils and neglecting the hillslope travel time in the hydrological model. The relationship is reported for (a) the study catchments, (b) specific classes of catchment area. The dashed line is the linear regression $d T_{n}=1.0014 \Delta_{1}-1.0019\left(r^{2}=1\right)$.
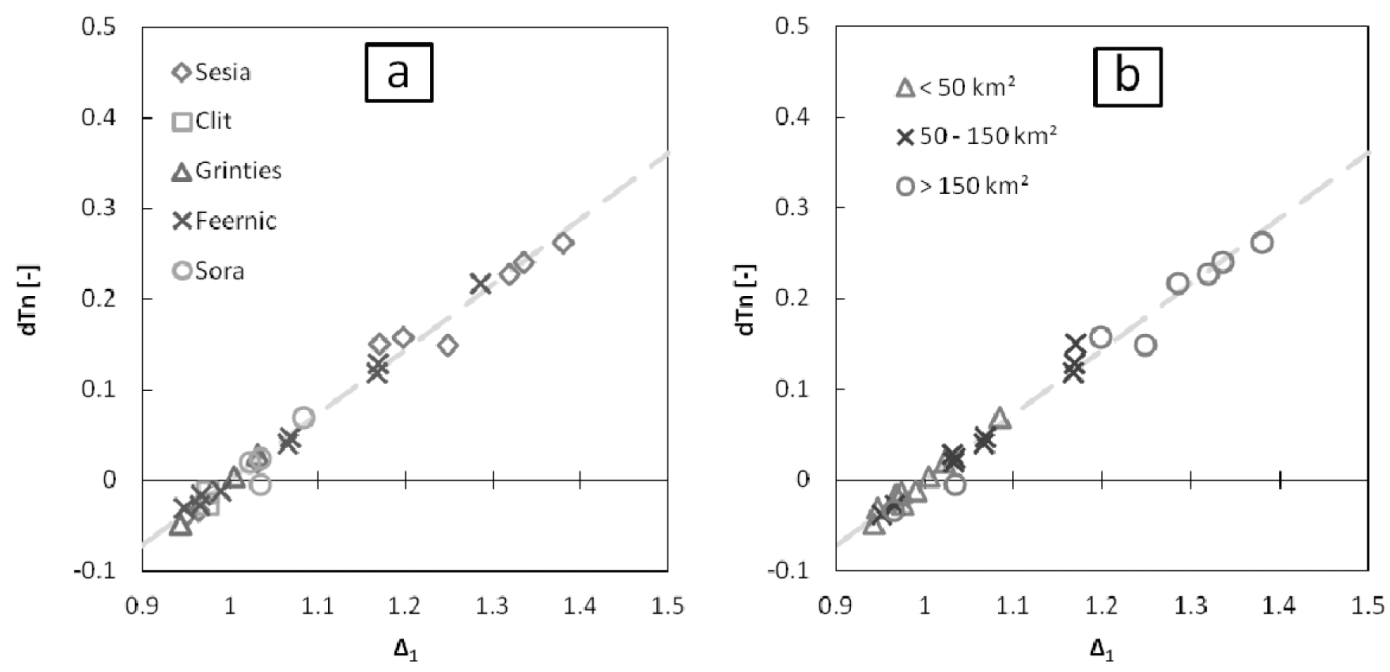

Fig. 5. (a, b): Relationship between $d T_{n}$ and $\Delta_{1}$ obtained by considering impervious soils and the hillslope travel time in the hydrological model. The relationship is reported for (a) the study catchments, (b) specific classes of catchment area. The dashed line is the linear regression $d T_{n}=0.72 \Delta_{1}-0.72\left(r^{2}=0.99\right)$.

and $\mathrm{b}$ is that the slope and the intercept of the linear regression are higher than those corresponding to Eq. (19). This effect is the result of the non-linearity characterizing the rainfall to runoff transformation. Zoccatelli et al. (2010), in an investigation concerning three extreme flood events, showed that the non-linearity in the rainfall-runoff transformation leads to a magnification of the values of the $d T_{n}$ statistics with respect to those obtained in the impervious case. Essentially, this means that when rainfall is either focused on the headwaters or on the outlet, the runoff exhibits an even stronger offset towards either the periphery of the catchment or the outlet as a result of the non-linear hydrological processes implied in the runoff generation. This effect leads to a steepening of the linear relationship between $d T_{n}$ and $\Delta_{1}$, which increases from 0.72 to 1.98 . Overall, the combination of the results displayed in Fig. 5a and b and Fig. 6a and b shows that the effect of the rainfall-runoff transformation on the relationship between $d T_{n}$ and $\Delta_{1}$ are stronger, at least for the considered case studies, than the effect of the hillslope residence time. An important implication of these results is 

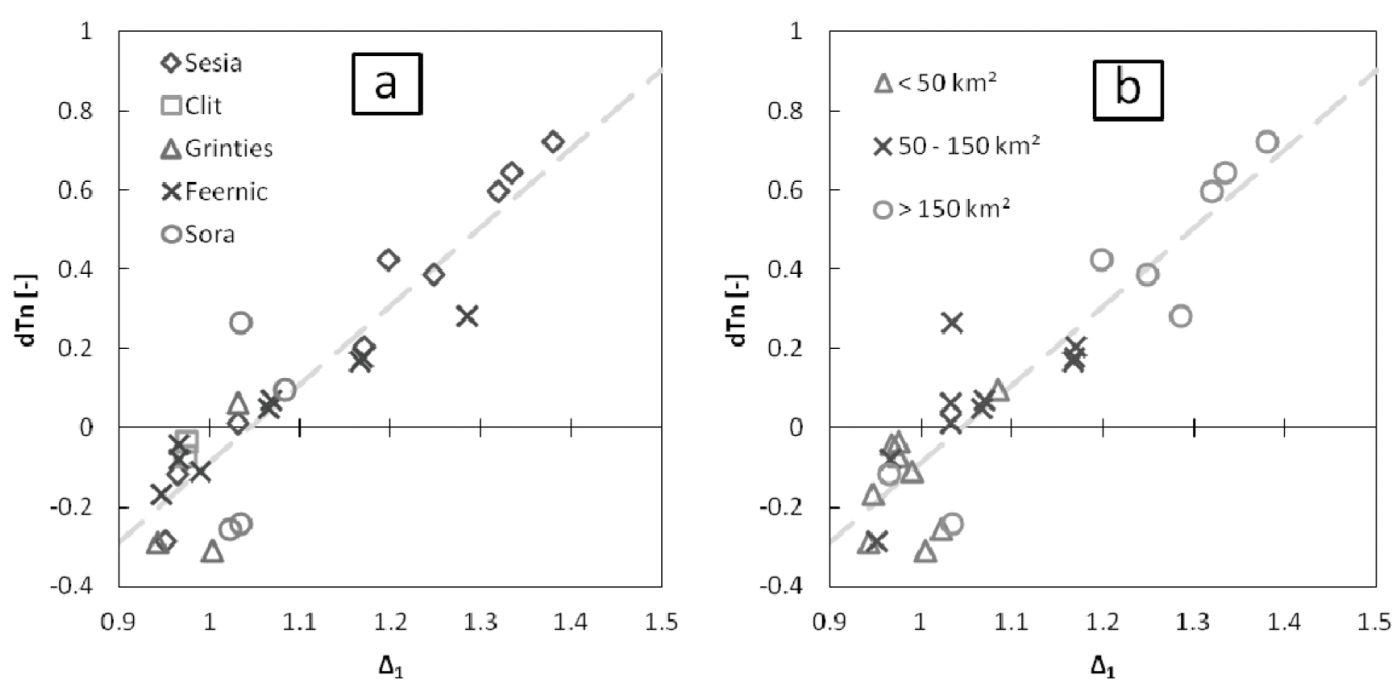

Fig. 6. (a, b): Relationship between $d T_{n}$ and $\Delta_{1}$ obtained by considering infiltration and the hillslope travel time in the hydrological model. The relationship is reported for (a) the study catchments, (b) specific classes of catchment area. The dashed line is the linear regression $d T_{n}=1.98 \Delta_{1}-2.07\left(r^{2}=0.83\right)$.

that the method based on the spatial moments provides useful information on the potential impact of the rainfall spatial organisation on the features of the ensuing flood hydrograph, in spite of the assumptions used for its derivation.

\section{Discussion and conclusion}

In this paper, we proposed a new set of spatial rainfall statistics which assess the dependence of the catchment flood response on the space-time interaction between rainfall and the spatial organization of catchment flow pathways. Named "spatial moments of catchment rainfall", these statistics describe the spatial rainfall organisation in terms of concentration and dispersion statistics as a function of the distance measured along the flow path coordinate. The introduction of the spatial moments of catchment rainfall permits derivation of the concept of catchment scale storm velocity, which quantifies the up or down-basin rainfall movement as filtered by the catchment morphological properties relative to the storm kinematics. The work shows how the first two spatial moments afford quantification of the impact of rainfall spatial organization on two fundamental properties of the flood hydrograph: timing (surrogated by the runoff mean time) and amplitude (surrogated by the runoff time variance). The first spatial moment provides a measure of the scaled distance from the geographical centroid of the rainfall spatial pattern to the catchment centroid. The second spatial moment provides a scaled measure of the additional variance in runoff time that is caused by the spatial rainfall organization, relative to the case of spatially uniform rainfall.
The analysis reported here suggests that the proposed rainfall statistics are effective in (i) describing the degree of spatial organisation which is important for runoff modelling and (ii) quantifying the relevance of rainfall spatial variability on flood modeling, with specific reference to the timing error. This is an essential aspect of this work, since our outcome clearly shows that catchment response is sensitive to spatial heterogeneity of rainfall even at small catchment sizes. The timing error introduced by neglecting the rainfall spatial variability ranges between $-30 \%$ to $72 \%$ of the corresponding catchment response time. It should be borne in mind that the floods considered in this work are very intense flash floods characterised by strong rainfall gradients.

We believe that the main strength of the method lies in a better understanding of the linkages between the characteristics of the rainfall spatial patterns with the shape and magnitude of the catchment flood response. This provides an indicator at catchment scale that integrates morphology and rainfall space-time distribution, and that can be used to compare influence of rainfall distribution across basins and scales. This is a fundamental aspect, since it enables evaluating the accuracy with which rainfall space and time distribution need to be observed for a given type of storm event and for a given catchment. For example, this may provide new statistics and criteria both for defining the optimality of raingauge network design in areas where flash floods are expected and for evaluating the accuracy of radar rainfall estimation algorithms and attendant space-time resolution.

The method proved to give reliable results in the context of flash floods. It would be useful to check the rainfall statistics and the methodology behind them for a wider variety of catchments and events, to explore how it can be extended to other cases. The statistics could also be used for assessing 
and quantifying hydrological similarity across a wide range of rainfall events and catchments, within the broader framework of comparative hydrology. For instance, the method can be used to identify the features of catchment morphology which attenuates (or magnify) the effects of rainfall spacetime organization. With the use of the spatial moments, the interaction of rainfall forcing and catchment characteristics can be described not only in terms of mean areal rainfall, but also by considering the features of rainfall spatial concentration and the storm velocity. For example, this may help to reveal the effect of orography not only on the precipitation accumulation at the catchment scale, but also on the spacetime organization of the rainfall patterns.

Further research should also focus on the concept of the catchment scale storm velocity. The introduction of this concept permits assessment of its significance for actual flood cases and analyses of the space and time rainfall sampling schemes which are required for its adequate estimation for various catchment scales and configurations. There is also a need to extend the formulation of the spatial moments of catchment rainfall to incorporate the hillslope transit time as a way to conceptualise the impact of the hillslope system on the catchment's filtering properties.

Finally, the rainfall statistics introduced in this paper could be used as an input to a new generation of semi-distributed hydrological models able to use the full range of statistics, and not only the mean areal rainfall, for flood modeling and forecasting. This will permit extending the capabilities of this class of hydrological models to rainfall events characterized by significant rainfall variability.

\section{Appendix A}

In this Appendix we show how Eqs. (10), (13) and (15) may be derived from V2010. For this, we start from Eqs. (19), (23) and (25) in V2010.

\section{A1 Derivation of Eq. (10)}

Equation (19) in V2010 (Eq. V19 hereinafter) provides the average time to route the rainfall excess from the geographical centroid of the rainfall spatial pattern to the catchment outlet. Using the same notation used in the current work, Eq. (V19) is written down as follows:

$E\left(T_{\mathrm{c}}\right)=\frac{g_{1}}{v}+\frac{\operatorname{Cov}_{x, y}\left[d(x, y), r_{t}(x, y)\right]}{v P_{0}}$

where $\operatorname{Cov}_{x, y}[]$ is the spatial covariance.

Equation A1 is developed as follows to derive Eq. (10):

$$
\begin{aligned}
& E\left(T_{\mathrm{c}}\right)=\frac{g_{1}}{v}+\frac{\operatorname{Cov}_{x, y}\left[d(x, y), r_{t}(x, y)\right]}{v P_{0}}= \\
& =\frac{g_{1}}{v}+\frac{\int_{A} d(x, y) r_{t}(x, y) d A}{A v P_{0}}-\frac{g_{1}}{v}=\frac{P_{1}}{P_{0} v}=\frac{\Delta_{1} g_{1}}{v}
\end{aligned}
$$

\section{A2 Derivation of Eq. (13)}

Equation (23) in V2010 (Eq. V23 hereinafter) provides the variance of the time to route the rainfall excess to the catchment outlet. Using the same notation used in the current work, Eq. (V23) is written down as follows:

$$
\begin{aligned}
& \operatorname{Var}\left(T_{\mathrm{c}}\right)=\frac{g_{2}-g_{1}^{2}}{v^{2}}+\frac{\operatorname{Cov}_{\mathrm{x}, \mathrm{y}}\left[d(x, y)^{2}, r_{t}(x, y)\right]}{v^{2} P_{0}}+ \\
& -\frac{\operatorname{Cov}_{x, y}\left[d(x, y), r_{t}(x, y)\right]}{v P_{0}}\left[2 \frac{g_{1}}{v}+\frac{\operatorname{Cov}_{x, y}\left[d(x, y), r_{t}(x, y)\right]}{v P_{0}}\right]
\end{aligned}
$$

Equation (A3) is developed as follows to derive Eq. (13):

$$
\begin{aligned}
& \operatorname{Var}\left(T_{\mathrm{c}}\right)=\frac{g_{2}-g_{1}^{2}}{v^{2}}+\frac{\int d(x, y)^{2} r_{t}(x, y) d A}{A v^{2} P_{0}}-\frac{g_{2}}{v^{2}} \\
& -\left(\frac{P_{1}}{P_{0} v}-\frac{g_{1}}{v}\right)\left(\frac{P_{1}}{P_{0} v}+\frac{g_{1}}{v}\right)= \\
& \left(\frac{P_{2}}{P_{0}}-\frac{P_{1}^{2}}{P_{0}^{2}}\right) \frac{1}{v^{2}}=\frac{\Delta_{2}\left(g_{2}-g_{1}^{2}\right)}{v^{2}} .
\end{aligned}
$$

\section{A3 Derivation of Eq. (15)}

Equation (25) in V2010 (Eq. V25 hereinafter) provides the covariance between the rainfall time and the routing time. Using the same notation used in the current work, Eq. (V25) is written down as follows:

$$
\begin{array}{r}
\operatorname{Cov}\left(T_{\mathrm{r}}, T_{\mathrm{c}}\right)=\frac{\operatorname{Cov}_{t}\left[T, \operatorname{Cov}_{x, y}[d(x, y), r(x, y, t)]\right]}{v P_{0}} \\
-\frac{\operatorname{Cov}_{t}\left[T, p_{0}(t)\right]}{P_{0}} \frac{\operatorname{Cov}_{x, y}\left[d(x, y), r_{t}(x, y)\right]}{v P_{0}}
\end{array}
$$

Equation (A4) is developed as follows to derive Eq. (15):

$$
\begin{aligned}
& \operatorname{Cov}\left(T_{\mathrm{r}}, T_{\mathrm{c}}\right)=g_{1} \frac{\operatorname{Cov}_{t}\left[T, \delta_{1}(t) w(t)\right]}{v}-g_{1} \frac{\operatorname{Cov}_{t}[T, w(t)]}{v} \\
& -\frac{\operatorname{Cov}_{t}[T, w(t)]}{v} \frac{\operatorname{Cov}_{x, y}\left[d(x, y), r_{t}(x, y)\right]}{P_{0}}= \\
& g_{1} \frac{\operatorname{Cov}_{t}\left[T, \delta_{1}(t) w(t)\right]}{v}-\frac{\operatorname{Cov}_{t}[T, w(t)]}{v}\left(g_{1}+\Delta_{1} g_{1}-g_{1}\right)= \\
& g_{1}\{\underbrace{\frac{\operatorname{Cov}_{t}\left[T, \delta_{1}(t) w(t)\right]}{v}}_{\text {term } 1}-\underbrace{\frac{\operatorname{Cov}_{t}[T, w(t)]}{v}}_{\text {term } 2} \Delta_{1}\} .
\end{aligned}
$$

Acknowledgements. The work presented in this paper has been carried out as part of the European Union FP6 Project HYDRATE (Project no. 037024) under the thematic priority, Sustainable Development, Global Change and Ecosystems and by the Research Project GEO-RISKS (University of Padova, STPD08RWBY).

Edited by: R. Uijlenhoet 


\section{References}

Andréassian, V., Perrin, C., Michel, C., Usart-Sanchez, I., and Lavabre, J.: Impact of imperfect rainfall knowledge on the efficiency and the parameters of watershed models, J. Hydrol., 250, 206-223, 2001.

Barry, D., Parlange, J.-Y., Li, L., Jeng, D.-S., and Crapper, M.: Green-Ampt approximations, Adv. Water. Res., 28, 1003-1009, doi:10.1016/j.advwatres.2005.03.010, 2005.

Bell, V. A. and Moore, R. J.: The sensitivity of catchment runoff models to rainfall data at different spatial scales, Hydrol. Earth Syst. Sci., 4, 653-667, doi:10.5194/hess-4-653-2000, 2000.

Berne, A., Delrieu, G., Creutin, J. D., and Obled, C.: Temporal and spatial resolution of rainfall measurements required for urban hydrology, J. Hydrol., 299, 166-179, 2004.

Blöschl, G.: Hydrologic synthesis: across processes, places, and scales, Water Resour. Res., 42, W03S02, doi:10.1029/2005WR004319, 2006.

Blöschl, G. and Sivapalan, M.: Scale issues in hydrological modelling: a review, Hydrol. Process., 9, 251-290, 1995.

Borga, M., Boscolo, P., Zanon, F., and Sangati, M.: Hydrometeorological analysis of the August 29, 2003 flash flood in the eastern Italian Alps, J. Hydrometeorol., 8, 1049-1067, 2007.

Borga, M., Gaume, E., Creutin ,J. D., and Marchi, L.: Surveying flash flood response: gauging the ungauged extremes, Hydrol. Process., 22, 3883-3885, doi:10.1002/hyp.7111, 2008.

Borga, M., Anagnostou, E. N., Blöschl, G., and Creutin, J. D.: Flash Floods: observations and analysis of hydrometeorological controls, J. Hydrol., 394, 1-3, doi:10.1016/j.jhydrol.2010.07.048, 2010.

Bouilloud, L., Delrieu, G., Boudevillain, B., Kirstetter, P.E.: Radar rainfall estimation in the context of post-event analysis of flash-flood events, J. Hydrol., 394, 17-27, doi:10.1016/j.jhydrol.2010.02.035, 2010.

D'Odorico, P. and Rigon, R.: Hillslope and channel contributions to the hydrologic response. Water Resour. Res., 39, 1113, doi:10.1029/2002WR001708, 2003.

Da Ros, D. and Borga, M.: Use of digital elevation model data for the derivation of the geomorphologic instantaneous unit hydrograph, Hydrol. Process, , 11, 13-33, 1997.

Davolio, S., Buzzi, A., and Malguzzi, P.: Orographic influence on deep convention: case study and sensitivity experiments, Meteorol. Z., 15 , 215-223, 2006.

De Lima, J. L. and Singh, V. P.: The influence of the pattern of moving rainstorms on overland flow, Adv. Water. Res, 25, 817828, 2002.

Ehret, U. and Zehe, E.: Series distance - an intuitive metric to quantify hydrograph similarity in terms of occurrence, amplitude and timing of hydrological events, Hydrol. Earth Syst. Sci., 15, 877896, doi:10.5194/hess-15-877-2011, 2011.

Fabry, F.: On the determination of scale ranges for precipitation fields, J. Geophys. Res., 101, 12819-12826, 1996.

Goltz, M. and Roberts, P. .: Using the Method of Moments to Analyze Three-Dimensional Diffusion-Limited Solute Transport From Temporal and Spatial Perspectives, Water Resour. Res., 23, 1575-1585, 1987.

Gourley, J., Hong, J., Flamig, Z. L., Wang, J., Vergara, H., and Anagnostou, E. N.: Hydrologic Evaluation of Rainfall Estimates from Radar, Satellite, Gauge, and Combinations on Ft. Cobb Basin, Oklahoma, J. Hydrometeorol., 12, 5, 973-988,
doi:10.1175/2011JHM1287.1, 2011.

Krajewski, W. F. and Smith, J. A.: Radar hydrology-rainfall estimation, Adv. Water. Res., 25, 1387-1394, 2002.

Maksimov, V. A.: Computing runoff produced by a heavy rainstorm with a moving center, Soviet Hydrology, 5, 510-513, 1964.

Marani, M.: Non-power-law-scale properties of rainfall in space and time, Water Resour. Res., 41, W08413, doi:10.1029/2004WR003822, 2005.

Marchi, L., Borga, M., Preciso, E., and Gaume, E.: Characterisation of selected extreme flash floods in Europe and implications for flood risk management, J. Hydrol, 394, 118-133, doi:10.1016/j.jhydrol.2010.07.017, 2010.

McDonnell, J. J. and Woods, R.: On the need for catchment classi?cation. J. Hydrol., 299, 2-3, doi:10.1016/j.jhydrol.2004.09.003, 2004.

Morin, E., Goodrich, D. C., Maddox, R. A., Gao, X. G., Gupta, H. V., and Sorooshian, S.: Spatial patterns in thunderstorm rainfall events and their coupling with watershed hydrological response, Adv. Water Res., 29, 843-860, doi:10.1016/j.advwatres.2005.07.014, 2006.

Moulin, L., Gaume, E., and Obled, C.: Uncertainties on mean areal precipitation: assessment and impact on streamflow simulations, Hydrol. Earth Syst. Sci., 13, 99-114, doi:10.5194/hess-13-992009, 2009.

Naden, P. S.: Spatial variability in flood estimation for large catchments: the exploitation of channel network structure, Hydrol. Sci. J., 37, 53-71, 1992.

Nicótina, L., Alessi Celegon, E., Rinaldo, A., and Marani, M.: On the impact of rainfall patterns on the hydrologic response, Water Resour. Res., 44, W12401, doi:10.1029/2007WR006654, 2008.

Niemczynowicz, J.: Investigation of the influence of rainfall movement on runoff hydrograph: Part I. Simulation of conceptual catchment, Nordic Hydrology, 15, 57-70, 1984.

Obled, C., Wendling, J., and Beven, K.: Sensitivity of hydrological models to spatial rainfall patterns: An evaluation using observed data, J. Hydrol, 159, 305-333, 1994.

Ogden, F. L. and Julien, P., Y.: Runoff model sensitivity to radar rainfall resolution, J. Hydrol, 158, 1-18, 1994.

Ogden, F. L. and Saghafian, B.: Green and Ampt infiltration with redistribution, J. Irrig. Drain. Eng., 123, 386-393, 1997.

Ogden, F. L., Richardson, J. R., and Julien, P. Y.: Similarity in catchment response: 2. Moving rainstorms, Water Resour. Res., 31, 1543-1547, 1995.

Pellarin, T., Delrieu, G., Saulnier, G. M., Andrieu, H., Vignal, B., Creutin, J. D.: Hydrologic visibility of weather radar systems operating in mountainous regions: Case study for the Ardeche Catchment (France), J. Hydrometeorol., 3, 539-555, 2002.

Rinaldo, A., Botter, G., Bertuzzo, E., Uccelli, A., Settin, T., and Marani, M.: Transport at basin scales: 1. Theoretical framework, Hydrol. Earth Syst. Sci., 10, 19-29, doi:10.5194/hess-1019-2006, 2006.

Robinson, J., Sivapalan, M., and Snell, J.: On the relative roles of hillslope processes, channel routing, and network geomorphology in the hydrologic response of natural catchments., Water Resour. Res., 31, 3089-3101, 1995.

Rodriguez-Iturbe, I. and Valdes, J. B.: The geomorphologic structure of hydrologic response, Water Resour. Res., 15, 1409-1420, 1979.

Rodriguez-Iturbe, I., Marani, M., D’Odorico, P., and Rinaldo, A.: 
On spacetime scaling of cumulated rainfall fields, Water Resour. Res., 34, 3461-3469, 1998.

Saco, P. and Kumar, P.: Kinematic dispersion in stream networks - 1. Coupling hydraulic and network geometry, Water Resour. Res., 38, 1244, doi:10.1029/2001WR000695, 2002.

Sangati, M., Borga, M., Rabuffetti, D., and Bechini, R.: Influence of rainfall and soil properties spatial aggregation on extreme flash flood response modelling: an evaluation based on the Sesia river basin, North Western Italy, Adv. Water. Res, 32, 1090-1106, 2009.

Saulnier, G. and Le Lay, M.: Sensitivity of flash-flood simulations on the volume, the intensity, and the localization of rainfall in the Cevennes-Vivarais region (France), Water Resour. Res., 45, W10425, doi:10.1029/2008WR006906, 2009.

Singh, V. P.: Effect of the direction of storm movement on planar flow, Hydrol. Process., 12, 147-170, 1998.

Skøien, J. O. and Blöschl, G.: Catchments as space-time filters - a joint spatio-temporal geostatistical analysis of runoff and precipitation, Hydrol. Earth Syst. Sci., 10, 645-662, doi:10.5194/hess10-645-2006, 2006.

Skøien, J. O., Blöschl, G., and Western, A.: Characteristic space scales and timescales in hydrology, Water Resour. Res., 39, 1304. doi:10.1029/2002WR001736, 2003.

Smith, J. A., Baeck, M. L., Morrison, J. E., Sturdevant-Rees, P. L., Turner-Gillespie, D. F., and Bates, P. D.: The regional hydrology of extreme floods in an urbanizing drainage basin, J. Hydrometeorol., 3, 267-282, 2002.

Smith, J. A., Baeck, M. L., Meierdiercks, K. L., Nelson, P. A., Miller, A. J., and Holland, E. J.: Field studies of the storm event hydrologic response in an urbanizing watershed, Water Resour. Res., 41, W10413, doi:10.1029/2004WR003712, 2005.

Smith, M. B., Seo, D.-J., Koren, V. I., Reed, S., Zhang, Z., Duan, Q.-Y., Cong, S., and Moreda, F.: The distributed model intercomparison project (DMIP): motivation and experiment design, J. Hydrol., 298, 4-26, 2004a.

Smith, M., Koren, V., Zhang, Z., Reed, S., Pan, J., and Moreda, F.: Runoff response to spatial variability in precipitation: an analysis of observed data, J. Hydrol., 298, 267-286, 2004b.
Surkan, A. J.: Simulation of storm velocity effects of flow from distributed channel network, Water Resour. Res., 10, 1149-1160, 1974.

Syed, K., Goodrich, D., Myers, D., and Sorooshian, S.: Spatial characteristics of thunderstorm rainfall fields and their relation to runoff, J. Hydrol., 271, 1-21, 2003.

Viglione, A., Chirico, G. B., Woods, R., and Blöschl, G.: Generalised synthesis of space-time variability in flood response: An analytical framework, J. Hydrol., 394, 198-212, doi:10.1016/j.jhydrol.2010.05.047, 2010a.

Viglione, A., Chirico, G. B., Komma, J., Woods, R., Borga, M., and Blöschl, G.: Quantifying space-time dynamics of flood event types, J. Hydrol., 394, 213-229, doi:10.1016/j.jhydrol.2010.05.041, 2010b.

Woods, R.: A search for fundamental scales in runoff generation: combined field and modelling approach, Ph.D. Thesis, Department of Environmental Engineering, University of Western Australia, Nedlans, Western Australia, 1997.

Woods, R. A. and Sivapalan, M.: A synthesis of space-time variability in storm response: Rainfall, runoff generation and routing, Water Resour. Res. , 35, 2469-2485, 1999.

Zhang, Y., Smith, J. A., and Baeck, M. L.: The hydrology and hydrometeorology of extreme floods in the Great Plains of eastern Nebraska, Adv. Water Resour., 24, 1037-1050, 2001.

Zanon, F., Borga, M., Zoccatelli, D., Marchi, L., Gaume, E., Bonnifait, L., and Delrieu, G.: Hydrological analysis of a flash flood across a climatic and geologic gradient: the September 18, 2007 event in Western Slovenia, J. Hydrol., 394, 182-197, doi:10.1016/j.jhydrol.2010.08.020, 2010.

Zoccatelli, D. and Wuletawu, R.: Role of hillslope and channel residence time on runoff model sensitivity to spatial rainfall organization, Report of University of Padova, 74 pp., 2010.

Zoccatelli, D., Borga, M., Zanon, F., Antonescu, B., and Stancalie, G.: Which rainfall spatial information for flash flood response modelling? A numerical investigation based on data from the Carpathian range, Romania, J. Hydrol., 394, 148-161, doi:10.1016/j.jhydrol.2010.07.019, 2010. 